\title{
The Rationale for Optimization of Higher Education Institutions' Allocation of Available Resources
}

\author{
Lyudmila Oleynikova \\ Department of Fiscal policy and tax \\ regulation \\ Academy of Financial Management \\ Kyiv, Ukraine \\ oleynikova.mila@ukr.net
}

\author{
Valentyna Helman \\ Personnel management and marketing \\ department \\ Zaporizhzhia National University \\ Zaporizhzhia, Ukraine \\ smsvell@yandex.ua \\ Yuriy Chuchuk* \\ Department of Accounting and \\ Taxation \\ Ivano-Frankivsk National Technical \\ University of Oil and Gas \\ Ivano-Frankivsk, Ukraine \\ yuriy.chuchuk@gmail.com
}

\author{
Iryna Halushchak \\ Department of accounting and auditing \\ Precarpathian national university by \\ Vasyl Stephanyk \\ Ivano-Frankivsk, Ukraine \\ iryna.galushchak@gmail.com
}

\begin{abstract}
The funding models of higher education institutions' activities were investigated. The regulatory practice in determining the resources levels used as a method of budget allocation was studied. The trends of changes in the budget expenditure on education were researched. Based on the time trend lines, the single-factor forecast models for the consolidated Ukrainian budget expenditure on education were built by using the Excel program. The methods of calculating the cost of tuition per student and budgetary programs formation based on essentially new funding mechanisms and given the new conditions in the labour market were defined. The problematic issues of funding higher education institutions in modern conditions were revealed. The main priorities of education and science funding reform were outlined; the need to implement the allocation of budgetary funds for higher education institutions was defined, with the core funding to be formed on the basis of calculating the average cost of one specialist training, and part of the formula to be used to encourage education institutions to achieve results. The methodological approaches to determining the cost of education services were offered given the international accounting standards and experience of post-socialist EU countries, a client-oriented model for determining tuition fees and the developments, including standard regulations for attractive credit resources which can be used by the private sector for training. In order to stimulate private investment in EU science, it is suggested using tax incentives for higher education institutions.
\end{abstract}

Keywords-Budgetary funds, funding, education, scientific developments, budget, planning, trend, forecast model, costs.

\section{PROBLEM STATEMENT}

Inefficient use of budgetary funds and special funding, reluctance to transform management approaches in funding higher education institutions(HEIs) and this area commercialization, alack of willingness to offer educational products of high-quality and interest for business as well as relevant applied scientific developments, increased competition from foreign HEIs (especially those of Poland and the Czech Republic) are the most crucial factors affecting HEIs' financial and physical conditions. The resolution of the above issues requires time and appropriate institutional and managerial support.

\section{RESULTS}

In Ukraine, the innovations in the budget area (transition to a medium-term budget planning) and changes in the approaches to budget allocations, reflected in the new version of the Law on Education and 2015-2017 by-laws, proved the necessity to alter the approaches to allocation of budgetary funds. The funding model should be customeroriented in provision of public services in higher education and evolutionary transformation of the existing financial accounting systems in education institutions, calculation of tuition cost per student and budgetary programs formation based on essentially new funding mechanisms and given the new conditions in the labour market. However, the implementation of the customer-oriented tasks should take place gradually, based on an iterative process of promoting reforms thus introducing new methodological approaches to tuition fees calculation, new standards of financial accounting in the public sector on grounds of the modernized philosophy of budgeting.

In 2016, by order of the Ministry of Education and Science of Ukraine, the Academy of Financial Management (Recommendations of the Ministry of Education and Science of Ukraine No 1/9-521 dated 3 October 2016 and No 1/9-218 dated 21 April 2017) collected the data on tuition fee sat different HEIs of Ukraine. The information was collected based on the reports of 160 HEIs in Ukraine (at the stage of data processing, false as well as less than reliable or complete data were eliminated) in the context of specialties providing training at the master and bachelor levels combined under the areas of scientific training in these education institutions. Based on the study results [1], we can compare the tuition fees in different HEIs as well as in the context of areas of training and to study the main trends regarding the features of the cost formation in the context of training levels and specialties. Thus, according to the results of the analysis of these HEIs, the 2015 weighted average tuition fee per full-time publicly-funded bachelor in 
the context of subject fields ranged from UAH 22350 (Law Schools) to UAH 40024 (Arts Schools). At the same time, the cost of HEI students training in Veterinary Medicine, Health, Culture and Arts was the highest, while the training of bachelors in the fields of Social and Behavioural Sciences, Journalism, Management and Administration, Law, Social Work was the least expensive.

According to the Decree of the Cabinet of Ministers of Ukraine "On approval of the calculation methods of the estimated cost of tuition per skilled worker, technician, graduate student, doctoral candidate" No 346 dated 20 May 2013, the data on the tuition fee sat HEIs included academic scholarships, which, in 2015, were funded from the budget. At the same time, some components of the tuition fees were only partially financed from the budget; mainly, they were financed from the Special HEI Fund. These components include costs of utilities and energy, maintaining dormitories, costs directly related to training and indirectly related to training, which distorts the results of calculations. It should be stressed that in recent years, the main problem in the system of education funding has been its under financing and optimization of the number of partiallyfunded budget programs, which hinders the implementation of a quality process of education (there was a significant reduction in budget programs: from 40 programs in 2016 down to 27 programs in 2017). Insufficient ability to introduce advanced technologies in education is caused by a lack of adequate funding, at least, for already approved budget programs.

Thus, returning to the problem of changing the quality of education services, we should pay attention to the HEI costs structure. Budget allocations primarily provided funding of state HEIs' costs of scholarships, partially - salaries and utility bills. This is due to the fact that the standard method of determining the amount of funding, which was used as a method of budgetary funds allocation, involves their adjustment towards reduction due to a lack of budgetary funds.

The data presented in Figure 1 is an evidence of the dynamics of the consolidated budget expenditure on education within the last decade.

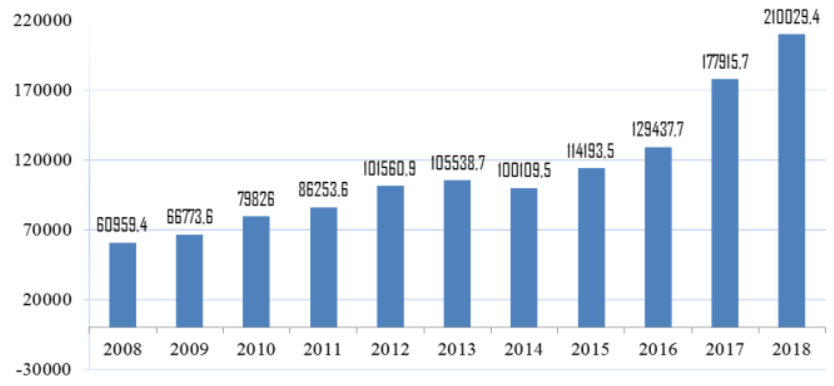

Fig. 1. The expenditure on education in the consolidated budget of Ukraine in 2008-2018, UAH million.

Note: developed by the author based on [2-5]

The analysis of the education funding dynamics in Ukraine in 2008-2018 shows a general trend towards funding increase by UAH 149070 million, from UAH 60959.4 million in 2008 to UAH 210029.4 million in 2018 respectively.
Under Article 78 of the Law of Ukraine "On Education" No 2145-VIII dated 5 September 2017, the state must ensure the total allocation to education of $7 \%$ of the gross domestic product (GDP) at least for account of the state budget, local budgets and other funding sources warrantable by laws.

During the entire period of independence of Ukraine, the indices of education funding provided for by the law have never been met. The state continues to view expenditure on education as an element of social policy rather than investment in human capital, which threatens the country's future development. In recent years, Ukraine has spent approximately $5.3 \%$ of the GDP on education from budgets of different levels, including special funds filled with payments of legal entities and individuals. The volume of expenditure on education from the State budget of Ukraine does not exceed $3 \%$ of the GDP [6].

The processes of budget decentralization, which started in 2015, resulted in a trend towards reducing the share of education expenditure in the state budget and correspondingly increasing in the expenditures of local budgets. According to the data of the Ministry of Finance of Ukraine [2], in 2015, the expenditure on education was allocated by various budget types: $26.4 \%$ was allocated from the state budget, $73.6 \%$ - from local budgets respectively; in 2016: $26.9 \%$ - from the state budget, $73.1 \%$ - from local budgets; in 2017: 23,1 \% - from the state budget, $76,9 \%$ - from local budgets; in $2018-21.1 \%$ from the state budget, $78.9 \%$ - from local budgets.

The index dynamics of the education expenditure share in the total expenditure of the consolidated budget of Ukraine during 2008-2018 is given in Figure 2.

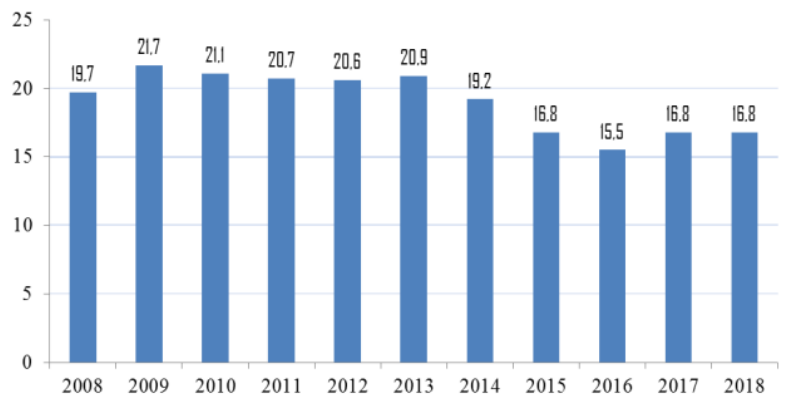

Fig. 2. The share of expenditure on education in the consolidated budget of Ukraine in 2008-2018, \%

Note: developed by the author based on [2-5]

Thus, a significant reduction of $15.5 \%$ in the share of expenditure on education in the consolidated budget of Ukraine was recorded in 2016, following the processes of budget decentralization, which started in 2015. However, owning to the efforts of the Government and the Ministry of Education and Science of Ukraine, there was an increase of $16.8 \%$ in education expenditure in 2017-2018.

The presented dynamics is evidence of the general trend towards decreasing the share of public expenditure on education in the consolidated budget. Since education funding is a priority area of budget expenditures at all levels, we shall make a forecast of education expenditure based on the data of the period from 2008 to 2018 . 
To build a single-factor forecast model of expenditure on education in the consolidated budget of Ukraine, we are to research the trends of changes in the data of the dynamic series shown in Figure 1, using time trends:

$$
\begin{gathered}
\text { linear } y=a t+b \\
\text { quadratic } y=a t^{2}+b t+c \\
\text { exp onential } y=a e^{b t}
\end{gathered}
$$

where $a, b, c$ - unknown parameters of the function;

$y$ - expenditure on education in the consolidated budget of Ukraine, UAH million;

\section{$t$ - sequence number of the period under research.}

Table 1 presents a forecast model, built in Excel using the trend lines. Based on the calculated model, the expenditure on education in the consolidated budget of Ukraine was forecast.

TABLE I. TYPE OF TIME TREND FUNCTION THE FORECAST MODEL

\begin{tabular}{|l|c|c|c|}
\hline $\begin{array}{c}\text { Type of } \\
\text { time trend } \\
\text { function }\end{array}$ & Forecast model & $\begin{array}{c}\text { Correlation } \\
\text { coefficient } \boldsymbol{r}\end{array}$ & $\begin{array}{c}\text { Forecast for } \\
\mathbf{2 0 1 9} \text {, UAH } \\
\text { million }\end{array}$ \\
\hline linear & $\mathrm{y}=12665 \mathrm{t}+36063$ & 0,844 & 188043 \\
\hline quadratic & $\begin{array}{c}\mathrm{y}=1457 \mathrm{t}^{2}-4825 \mathrm{t} \\
+73960\end{array}$ & 0,931 & 159268 \\
\hline exponential & $\mathrm{y}=54119 \mathrm{e}^{0,11 \mathrm{t}}$ & 0,932 & 202590,2 \\
\hline
\end{tabular}

Since the values of the $r$ coefficients approach one, on the basis of these models a forecast for the expenditure on education in the 2019 consolidated budget of Ukraine was developed. The time trends built enable us to conclude that the exponential trend approximates the statistical data in the most appropriate way. According to the exponential forecast model, the expenditure on education in the 2019 consolidated budget of Ukraine will make up UAH 202590.2 million that is by UAH 7439.2 million less than in 2018 .

In the context of the lack of budget funds and existing general trend towards reducing the share of public spending on education in the consolidated budget during 2008-2018, the projected figures of the expenditure on education in the consolidated budget of Ukraine suggest paying special attention to the problems of education in Ukraine, processes of education reform, effective allocation and use of budget funds.

According to the calculations of the Academy of Financial Management [1] in the framework of the abovementioned study, in 2015, the average cost of tuition per publicly funded under graduate student accounted for UAH 28.4 thousand per year, in 2016 - UAH 30.6 thousand respectively. At the same time, this fee included the following main costs: costs directly and indirectly related to education (mainly professors' salaries - 60-64\% of the cost), scholarship costs excluded; costs of academic scholarships and social welfare of students (29-33\%); utilities and maintenance (7\%); capital expenditure $(0.1 \%)$.

This structure of costs will not significantly change the education process quality in the country. Creation of a client-oriented model for determining the cost of students' training based on the alterations in the provisions of the Resolution of the Cabinet of Ministers of Ukraine "On determining the cost of education services" (the costs of scholarships, social protection, scientific research to be excluded from the cost structure) and given the international accounting standards and experience of post-socialist EU countries, and the developments, including standard regulations for attractive credit resources, which can be involved by the private sector for training, constitute an important preparation stage for performance of the work on development of a new model for allocation of education subventions for higher education.

It should be noted that the main priorities of the education and science funding reform include the need for introduction of a formula distribution of budget allocations for HEIs, with the core funding to be formed on the basis of calculating the average cost of tuition per specialist, and part of the formula to be used to encourage education institutions to achieve results. At the transition stage, the formula basic component should take into account the historical experience, and the subvention distribution should be based on two components, where some part of the subvention should cover the current costs of education process, and other part should take into account the indicative characteristics based on the scientific potential of institutions, effectiveness of the teaching staff and efficiency of the HEI management component. Development of indicative characteristics for the subventions distribution formula in the transition period is the main purpose of work when developing new approaches to HEIs funding. However, it is necessary to take into account the existing experience of applying the coefficients depending on the field of study (11 groups), the students are trained in, or according to another principle (6 groups), which will enable adjusting the cost of tuition depending on the subject area, training level, possibly - the HEI location, or other conditions

At the workshop in the Ministry of Education and Science, the possibility of alternative grouping (contrasted to the one offered by the Academy of Financial Management) was discussed. It included 6 groups: Humanities, Social and Behavioural Sciences, Journalism, Management and Administration, Law, Social Work, Servicing; Technology, Education, Mathematics and Statistics; Mechanical Engineering, Electrical Engineering, Automation and Instrumentation, Electronics and Telecommunications, Manufacturing and Technology, Transport, Architecture and Construction; Chemical and Bioengineering, Agricultural Sciences and Foodstuff, Biology, Natural Sciences; Veterinary Medicine, Healthcare; Culture and Art, where each group will apply the appropriate coefficient to be calculated for each group on an objective basis. Based on the existing data, it was suggested that the group "Humanities, Social and Behavioural Sciences" should be considered as the basic one with the coefficient of 1 .

One of the main issues that will significantly affect the future allocation of funds to both higher education and education in general is the growth of the national economy, its structure and potential in the medium and long terms. The transition to medium-term budget planning is a very important step but not a sufficient one. However, the 
economy structure greatly affects the labour market formation and hence the prospects for the development of certain groups of specialties and subject areas, structuring of education by levels, etc. Due to the lack of clear prospects for the economy development, there is uncertainty about the reforms in education and definition of priorities.

The indices of public expenditure on science in Ukraine also show a downward trend. In 2015, their share in the GDP accounted for $0.21 \%$, while in 2014 , according to the OECD data, in the Member States the average expenditure on research from all sources amounted to $2.37 \%$ of the GDP and was characterized by the ratio of public capital to private capital approximately as 1:2 (USD 0.79:1.58). In some countries, there was the prevalence of public expenses over private ones or approximate parity of sources in the science funding models, namely in Chile, the Czech Republic, Estonia, Greece, Italy, Luxembourg, Mexico, New Zealand, Norway, Poland, Portugal, Slovakia [7]. The Lisbon Treaty and the Europe 2020 Strategy for economic growth provide for investing 3\% of the EU GDP in science, technology and innovation. According to the Report on the Development of the Common Scientific Area, in 2014, up to $55 \%$ of researchers in European countries worked in stateowned institutions. The research funding was carried out both on the program-target principle and institutional (basic) one.

Given the above-stated, the main problems in the science and education funding in Ukraine include the following:

- non-availability of the new established funding mechanisms that would ensure a high quality of education and science;

- inability to attract credit resources for funding education by households due to their high cost;

- in efficient spending of budgetary funds in the fields of education and science (primarily through the unestablished criteria of socio-economic efficiency as well as insufficient level of application of the principle of "evidence-based knowledge transfers" [8]);

- a low level of private investment in the development of science, which is caused, on the one hand, by poor financial condition of enterprises during the financial and economic recession, and, on the other hand, by the unformed demand of business entities for innovation as well as lack of practically-oriented research and development due to insufficient demand for innovation;

- a low level of international grants attraction due to insufficient integration of Ukrainian scientists into the Common Scientific (Research) Area;

- transfer of authority to fund vocational education from the state budget to local budgets without proper elaboration of premises for attracting regional private capital to this area, in particular with the prospects of public-private partnership (PPP);

- insufficient development of institutions of public control over efficient use of public financial resources, given the branch specific features.
In the EU countries, there are various education funding models, which differ in the private and public funding ratio, but the common thing for them is a combination of different funding sources.

With the aim of stimulating private investment in science in the EU such tax incentives as tax deductions or tax credit for R\&D are used. These deductions are usually made from the enterprise's capital gains tax; in some countries (the Netherlands) there is also a deduction from contributions to social insurance of employees engaged in R\&D

In some countries, tax deductions for $R \& D$ allow reducing the tax base size for the amount, which exceeds the actual costs of these activities. For instance, in the UK, the discount for large companies is $130 \%$ of $\mathrm{R} \& \mathrm{D}$ costs; for small and medium-sized companies it accounts for $225 \%$. In addition, when small and medium-sized companies, which carry out R\&D, incur losses, the state compensates $24.75 \%$ of such losses. In the Netherlands, the deduction rate accounts for $154 \%$. In most other countries, however, only part of the R\&D costs is compensated by the deduction (for instance, in Spain the deduction rate makes up 25\%).

\section{CONCLUSIONS}

Thus, taking into account the international experience, Ukraine needs to focus on the formation of an intermediate model of funds allocation within the budget funding of HEIs of III and IV accreditation levels, which is associated with the need for evolutionary introduction of a customeroriented model of public services in higher education and investment in education. Such models are being discussed in the framework of consultations with representatives of the EU Member States and in the expert community. It should be noted that state HEIs are non-profit organizations. The models currently under discussion should not contain such a concept as "profit". Therefore, the financial outcome obtained should be directed to the HEI Development Fund, which finances investments. However, in practice, statebacked HEIs neither receive such funds nor have the funds that are significant and sufficient for investments.

In addition, the amount of state-backed budget funding for education does not practically cover capital expenses due to the limited budget funds. The current demographic situation (reduction in the number of applicants) does not allow unreasonably increasing the cost of tuition under the contract, including investment costs into it.

Therefore, there is a natural need to optimize the allocation of available HEIs' resources, which will enable allocation of funds for investment costs.

\section{REFERENCES}

[1] I. Bohdan, Information and analytical report for the results of generalizing the indicators of the financing of educational institutions of Ukraine, Data analysis report based on the generalization of the indices of funding education institutions of Ukraine, Kyiv, Ukraine: AFU, 2017. [in Ukrainian].

[2] Official site of the Ministry of Finance of Ukraine, 2019. [Online]. Available: https://index.minfin.com.ua/ua/finance/. Accessed on: August 22, 2019. [in Ukrainian]

[3] The Division of State Finance Statistics of the Department of State Budget of the Ministry of Finance of Ukraine. Statistical Collection: «Budget of Ukraine 2017», 2018. [Online]. Available: https://www.minfin.gov.ua/uploads/redactor/files/Budget\%20of\%20U 
kraine $\% 202017 \% 20$ (publish).pdf. Accessed on: August 22, 2019. [in Ukrainian].

[4] I. Ye. Verner, O. A. Vyshnevska, The 2016 Statistics Yearbook of Ukraine, State Statistics Service of Ukraine, 2016. [Online]. Available: https://ukrstat.org/uk/druk/publicat/Arhiv u/01/ Arch_zor_zb.htm. Accessed on: August 2, 2019. [in Ukrainian].

[5] O. H. Osaulenko, O. E. Ostapchuk, The 2011 Statistics Yearbook of Ukraine, Kyiv, Ukraine: AvhustTreid, 2012. [Online]. Available: https://ukrstat.org/uk/druk/publicat/Arhiv_u/01/ Arch_zor_zb.htm. Accessed on: July 25, 2019. [in Ukrainian].

[6] Verkhovna Rada of Ukraine. (2017, July 27). Reccomendations of the Parliamentary Hearings No 2133-VIII, On the state and problems of education and science funding in Ukraine. [Online]. Available: https://zakon.rada.gov.ua/laws/show/2133-19. Accessed on: July 28, 2019. [in Ukrainian].

[7] Organisation for Economic Cooperation and Development, Main Science and Technology Indicators, OECDStat, 2019. [Online]. Available:

http://stats.oecd.org/Index.aspx?DataSetCode=MSTI_PUB. Accessed on: August 12, 2019. [in Ukrainian].

[8] A. Wiseburg, «Conclusionsand Future Steps: Evidence-based Knowledge Transfer?», Economicand Social Research Council, 2006. [Online]. Available: http://www.oecd.org/edu/ceri/37107848.pdf. Accessed on: August 10, 2019. [in Ukrainian]. 